\title{
Two Interpretations of Two Stoic Conditionals
}

\author{
Alan Hájek
}

Four different conditionals were known to the Stoics. The so-called 'first' (Philonian) conditional has been interpreted fairly uncontroversially as an ancient counterpart to the material conditional of modern logic; the 'fourth' conditional is obscure, and seemingly of little historical interest, as it was probably not held widely by any group in antiquity. The 'second' (Diodorean) and 'third' (Chrysippean) conditionals, on the other hand, pose challenging interpretive questions, raising in the process issues in philosophical logic that are as relevant today as they were then. This paper is a critical survey of some modern answers to four of the most tantalizing of these questions; the issues that I will discuss arise out of interpretations of the Diodorean and Chrysippean conditionals as expressions of natural law, and as strict implications. I will reject these interpretations, concluding with my own proposal for where they should be located on a 'ladder' of logical strength.

The following passage from Sextus will form the basis of my discussion (from Outlines of Pyrrhonism [Pyrrhoneae Hypotyposes], as presented by Long and Sedley 1987b, 211). He has just introduced Philo's account of "a sound conditional"-by which I understand a true conditional-with the example "when it is day and I am talking, "If it is day, I am talking'". He then continues: 


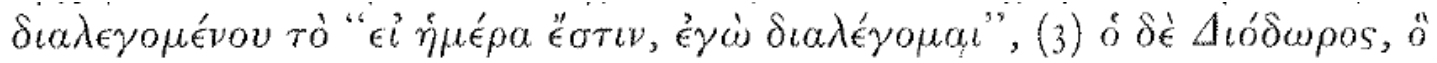

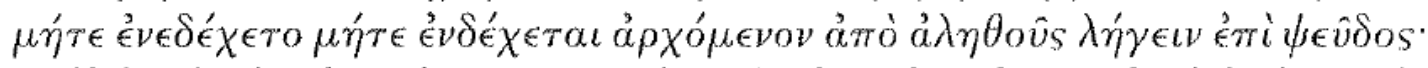

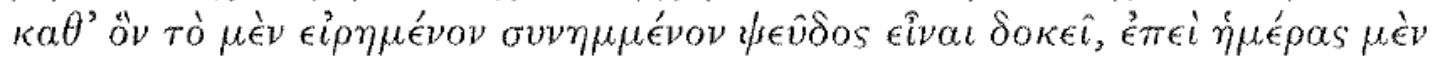

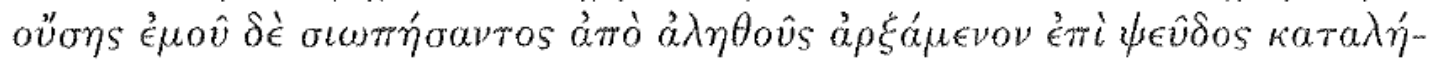

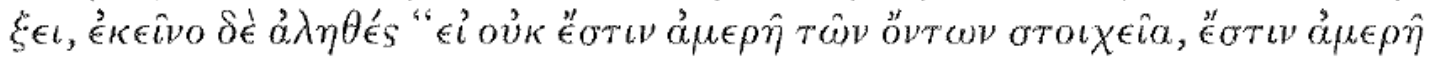

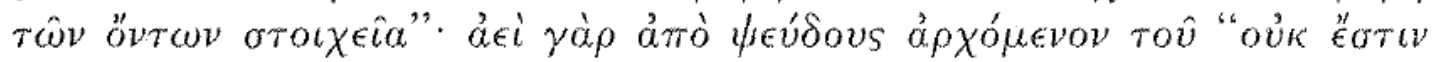

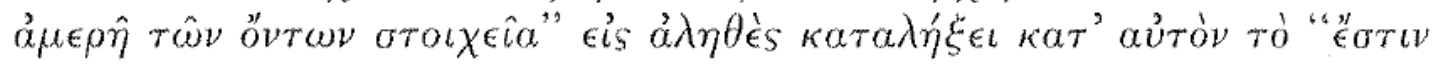

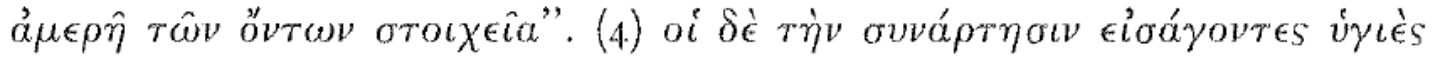

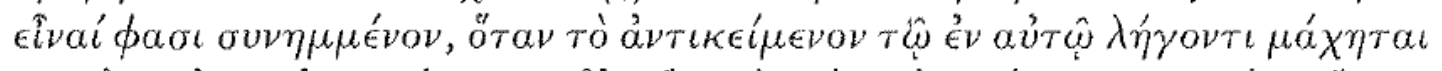

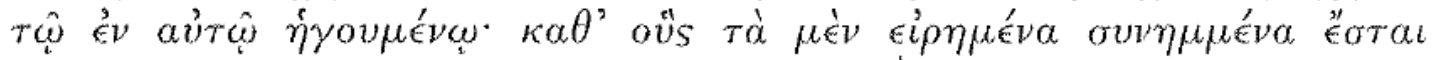

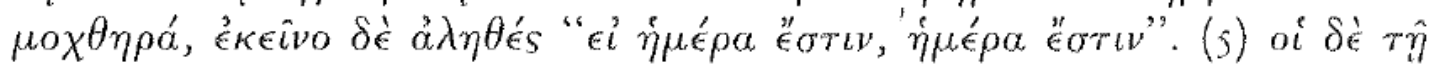

\section{!!NOTE TO TYPESETTER/COPY EDITOR: THE ABOVE GREEK}

PASSAGE IS A PDF fILE MADE FROM A PHOTOGRAPH: I AM

UNABLE TO PRODUCE SOME OF tHE DIACRITICAL MARKS

MYSELF, AND I AM ALSO UNABLE TO EDIT THIS PDF FILE.

tHE PASSAGE SHOULD BEgIN WITH “(3)" AND END

IMMEDIATELY BEFORE “(5)”-THAT IS, THE FIRST 3/4 OF LINE

1 AND the LAST $1 / 6$ OF the fINAL LINE SHOULD BE REMOVED, IF POSSIBLE!!

I will follow the Long and Sedley $(1987 a, 209)$ translation:

(3) Diodorus, on the other hand, says it is the one which neither was nor is able to have a true antecedent and a false consequent. On his view the aforementioned conditional seems to be false, since when it is day but I have fallen silent it will have a true antecedent and a false consequent, but the following one is true: 'If there are not partless elements of things, there are partless elements of things.' For it will always have the false antecedent 'There are not partless elements of things' and the (in his view) true consequent 'There are partless elements of things.' (4) Those who introduce 'cohesion' say that a conditional is sound whenever the contradictory of its consequent conflicts with its antecedent. On their view the aforementioned conditionals will be unsound, but the following one true: 'If it is day, it is day.'

(3) gives us insight into the Diodorean conditional, while (4) does so 
for the Chrysippean conditional.

\section{The Diodorean Conditional}

It will be convenient to symbolize the Diodorean conditional if $p$ then $q^{\prime}$ as

' $p \rightarrow_{\triangleright} q$ '. To understand his definition of a true conditional, with its appeal to the word "able", we must recall his views on modality. In particular, he identifies the things that are possible as "What either is or will be" (Long and Sedley 1987a, 231). Hence, his definition of a true conditional, $p \rightarrow_{\triangleright} q$, becomes:

(i) it is not and never will be true that $p$ and not $q$;

(ii) it never was nor was going to be true that $p$ and not $q$.

In short: whenever $p, q$. This much is relatively uncontroversial. The polemics begin with the problem of characterizing what these truth conditions amount to in modern vocabulary.

\section{Is the Diodorean conditional strict implication?}

Some modern authors have interpreted the Diodorean conditional as the ancient counterpart of strict implication-notably, Mates (1949). On this view, ' $\rightarrow_{\mathrm{D}}$ ' is what C. I. Lewis symbolized with his 'fishhook' $\rightarrow: p \rightarrow_{\triangleright} q$ is true if and only if the corresponding argument ' $p$; therefore $q$ ' is valid. Alternatively, this is to treat a conditional proposition as a material conditional governed by a logical necessity operator, i.e. $\square_{\iota}(p \supset q)$. This is true if and only if $p$ 
$\supset q$ is true in all logically possible worlds. We must firstly examine the nature of this 'necessity', both as Diodorus intends it, and as these modern authors intend it.

On Diodorus' conception, a proposition can change truth value over time. A proposition $p$ is necessary in the Diodorean sense just in case $p$ is true and will always be true-let us symbolize this by ${ }^{\prime} \square_{\mathrm{D}} p^{\prime}$. This makes no demands on the truth value of $p$ in the past, however. Thus, his truth conditions for a conditional is singularly strong, for he insists on its truth value being fixed for all time. I will now try to make this precise. Following Prior $(1957,19)$, we can introduce a modal operator ' $\square_{T}$ ' meaning 'at all times'. Then we may translate $p \rightarrow_{\circ} q$ as $\square_{\mathrm{T}}(p \supset q)$. Note that $\square_{\mathrm{T}}(p \supset q)$ is logically stronger than $\square_{D}(p \supset q)$ : the former implies the latter, but not vice versa. Thus, perhaps surprisingly, Diodorus imposes truth conditions on the conditional even stricter than his necessity conditions on the corresponding Philonian conditional. Furthermore, truth and necessary truth of Diodorean conditionals come to the same thingi.e. $\square_{\mathrm{T}} \square_{\mathrm{T}}(p \supset q)$ is equivalent to $\square_{\mathrm{T}}(p \supset q)$. This iterative property of the (temporal) necessity operator is distinctive of Lewis' modal system S4, and in fact Prior (1955) shows that the Diodorean definitions of the modal operators yield a system strikingly like S4.

Prior offers a reformulation of the Diodorean conditional, but his account is mistaken. He defines Fp as 'it will be the case that p', Gp $=-F-p$ ('it will always be the case that $p^{\prime}$ ), $L p=p \& G p$, and he then 
expresses $p \rightarrow_{\triangleright} q$ as $L(p \supset q)$. We may read this as 'it is the case, and always will be the case that $p$ materially implies $q^{\prime}$. This omits the fact that $p \rightarrow_{\triangleright} q$ should also include 'and it has always been the case that $p$ materially implies $q^{\prime}$. Prior has translated $\square_{\mathrm{D}}(p \supset q)$; however, as we have already remarked, the Diodorean conditional is stronger than the necessitation (in his sense) of the corresponding Philonian conditional. And this suggests what Diodorus' answer would be to the question that heads this section: "The conditional is not strict implication-it is something stronger!" Given his conception of necessity, he should say this. Note that I disagree here with Mates (1953), who thinks that given Diodorus' conception of necessity, he would think of his conditional as strict implication. To substantiate this, Mates notes (correctly) that "any conditional which would satisfy his requirements for truth would also satisfy his requirements for necessary truth" (47). But it is a mistake to assume that a Philonian conditional that is necessary in Diodorus' sense (i.e. a 'strict conditional' in his sense) would satisfy these requirements in the first place. We have seen why this is not the case.

Thus, we have seen that a great deal turns on Diodorus' seemingly perverse notion of necessity. In what sense, then, is the Diodorean conditional a 'true-in-all-possible-worlds' version of the Philonian conditional? (Our answer to this question will be another way of answering in what sense it is strict implication.) By a 'world' I will mean an instantaneous time-slice of the actual world. The actual 
world thus consists of uncountably many such temporal stages. A Diodorean conditional $p \rightarrow_{D} q$ is true (i.e. true in the actual world) if and only if the corresponding Philonian conditional is true at all these 'worlds'. This gives another interpretation to the necessity operator: we may read it as 'it is true at all temporal stages that'.

$\square_{T}$ is not, however, a logical necessity operator, and the picture we have just presented is quite distinct from one in which possible worlds are thought of as different ways the world logically might have been or might be. It is the latter picture which is appropriate for Lewis' strict implication. For now, $p \supset q$ must be necessarily true as matter of logic, irrespective of the way the world is or might have been. Nonetheless, Diodorean implication has been interpreted as implication in this strongest possible sense. Chisholm (1941, 49), for example, states this explicitly. However, as Mates points out (1953, 49), Chisholm has simply misinterpreted a passage of Sextus (which in fact deals with the Chrysippean conditional), so we will not detain ourselves here.

More interesting is Hurst's argument to the conclusion that Diodorus' definition is "practically equivalent" to Lewis' definition of strict implication $(1935,485)$. The force of the qualification "practically" is not intimated to us, and offhand it makes no senseequivalence does not admit of degrees. Judging by Hurst's comments elsewhere, it is in fact no qualification at all. She downplays the importance of Diodorus' temporal references, maintaining that "in stressing the temporal aspect Diodorus has 
missed the main point, and that he attached too much importance to this is shown by the use of the two tenses in his own definition" (486). I would venture to say, rather, that it is Hurst who has "missed the point". Firstly, Diodorus' two-pronged definition is not "unfortunate and unnecessary" (487) as Hurst believes (nor “redundant", as Mates 1953, 46 claims), but essential for handling the possibility that one or more of the propositions in the conditional may go out of existence, which he countenances. Secondly, as Mates comments (50), it is surely no accident that temporal references occur here, since they also occur in Diodorus' conceptions of modality.

Hurst rejects the interpretation in which a true Diodorean conditional is "that which, as a matter of fact, is always true" (which is in essence Mates' view). She believes that this criterion "would have the disadvantage of never being applicable with certainty" (488). A proponent of the view that she attacks might say that, since Diodorus saw knowledge as being dependent on the truth of conditionals, they could only be relied upon if they were always true, independent of their time of utterance. Hurst sees that in solving one epistemological problem, Diodorus would have created another one: how could we ever decide whether or not a conditional was true? To be sure, if a Diodorean conditional is false, then a corresponding Philonian conditional must have been, or must be (in a finite amount of time in the future) false, and to this extent its falsehood is knowable. However, if the conditional is in fact true, 
how can we ever know that it is? ${ }^{1}$

Mates deftly meets Hurst's objection again $(1953,50)$. The fact that this interpretation saddles Diodorus with an epistemological problem does not show that the interpretation is wrong (nor, I might add, that Diodorus' definition is ipso facto wrongheaded, if the interpretation is correct). Hurst argues, however, that since Diodorus does give an example of a true conditional, then the epistemological problem could not have been his. The example she cites is "If the elements of the existent are not without parts, then the elements of the existent are without parts" (489). Mates exposes her mistranslation of Sextus here: she has rendered the antecedent as the negation of an analytic sentence, when he offers instead "There do not exist atomic elements of things." This accords with the Long and Sedley translation (as quoted in my introduction): "there are not partless elements of things." Furthermore, I wonder why Hurst thinks that this example is decisive for her case. Given her mistranslation, it may indeed by a true strict implication, but then it is a fortiori a true implication in the temporal sense that we have attributed to Diodorus. This only shows that the epistemological problem is not as serious for Diodorus as Hurst

${ }^{1}$ I am reminded here of the undecidability of sets of formulae in the predicate calculus. To be sure, if a set $S$ is unsatisfiable, then a refutation of $S$ can be found in finitely many steps. However, if $S$ is in fact satisfiable, there will be no end to our search for a refutation, and we will not be able to conclude that it is satisfiable in finitely many steps. Replace "a set $S$ " by "a Diodorean conditional", "satifiable" by "true", "unsatisfiable" by "false", "refutation" by "a corresponding false Philonean conditional" and "finitely many steps" by "finite time" to almost get, mutatis mutandis, the corresponding epistemological problem for Diodorean conditionals. 
makes out-at least some analytically true conditionals can be known to be true.

It should be obvious now that I find the 'strict implication' interpretation of the Diodorean conditional untenable, at least insofar as this means the logical implication of C. I. Lewis. $\square_{\text {T }}$ should not be identified with logical necessity, $\square_{\llcorner}$, and so $p \rightarrow_{\mathrm{D}} q$, which I have translated as $\square_{\mathrm{T}}(p \supset q)$, should not be identified with $\square_{\mathrm{L}}(p \supset q)$. Let us move on, then, to another interpretation.

\section{Does the Diodorean conditional express natural law?}

I agree with Mates that “Diodorus managed to define a plausible sense of 'implication' that is stronger than Material implication and weaker than Strict implication" (239). Many believe that a law-like relation between two propositions, similarly, is intermediate in strength between material and strict implication. Perhaps, then, Diodorean conditionals have exactly the right strength to express law-like relations. This interpretation is complicated, however, by a further question. Are we to identify the Diodorean conditional with some $20^{\text {th }}$ century conception of natural law, or with a Stoic conception? I have not seen this question answered-or even posed -by those who put forward this interpretation. Any answer will be problematic. Our conceptions of natural law are varied and little agreed upon. There are 'Humean' or 'best systems' accounts (Lewis 1973), 'necessitarian' accounts (Pargetter 1984, McCall 1994, Vallentyne 1988), and 'universals' accounts (Dretske 1977, Tooley 
1987, Armstrong 1983). Some modern philosophers (e.g. van Fraassen 1989) even believe that there is no such thing as a law of nature! So claiming that Diodorean conditionals should be identified with laws of nature in some modern sense is nebulous indeed. On the other hand, there may be no identification with a Stoic conception of law to be had. For it is questionable whether the Stoics (at least at the time of Diodorus) even had a notion of 'law of nature'. (It is notable that while Long and Sedley have entries on such topics as their views on 'modality', 'causation and fate', and 'scientific methodology', there is none on 'law of nature' or any synonymous locution.) To explore whether there was such a notion in antiquity would be a separate, though worthwhile, project to the present one. For the moment, let us agree that this proposed identification has strong presuppositions, and move on to a closer examination of it.

Fortunately, the problems of exegesis do stop somewhere, even if not with the Stoics. For clearly Gould and Mueller attribute this interpretation of the Diodorean conditional to Mates. Gould (1967, 160) writes: “See Mates ... [1953] p. 48, for an implicit identification of Diodorean implication with a conditional which expresses a natural law." Mueller (1969) makes the attribution even more bluntly: "Mates suggests that a Diodorean conditional corresponds to natural law." However, this is somewhat unfair to Mates, and if we read him carefully, we will see that his position is more subtle. The relevant passage in his book (1953) is this: 
As an example of a true conditional [Diogenes] gives, "If it is day, it is light," and asserts that "It is not light" and "It is day" are incompatible. Now this conditional may have been regarded as analytic; if so, Diogenes' source refers to the third type of implication. The conditional may, however, have been considered as expressing a natural law; in this case Diogenes' source would perhaps have reference to Diodorean implication. (48)

Perhaps Mates goes too far in suggesting that the conditional "If it is day, it is light" may have been "considered as expressing natural law", simply because the Stoics of Diodorus' time may have had no such concept, as I have noted. But this is not Gould's or Mueller's point; they have presumably read the last half of the last sentence quoted here as Mates' 'identification'. But far from being an identification, I think that Mates is cautiously suggesting something that I will paraphrase as a conditional: “if Diogenes' example was considered as expressing natural law, then (perhaps) it is an example of Diodorean implication". Gould and Mueller are effectively paraphrasing Mates' view as a biconditional: “if and only if Diogenes' example was considered as ...". In short, I think that the most that we can glean from this snippet on Mates' view is that each natural law corresponds to a true Diodorean conditional; but he need not hold the converse (indeed, I doubt that he does). On my reading of him, Mates would regard the Diodorean conditional as being stronger than the Philonian, and at most as strong as lawful connection, but he does not commit himself to any more precise characterization than this.

Moreover, it is just as well that he does not make this alleged 
identification, as it would be unfortunate for a number of reasons. Firstly, laws of nature apparently entail corresponding counterfactuals. The law 'All $F s$ are $G s^{\prime}$ requires, among other things, that for every possible $x$, if it were an $F$, then it would be a $G$. The Diodorean conditional, however, might not have such counterfactual implications; and the Stoics had no account of (or interest in) counterfactuality as far as we know. Secondly, any Diodorean conditional with an impossible (in his sense) antecedent is vacuously true, yet such conditionals do not express any law-like connection. For example, we know that the following Diodorean conditional is vacuously true: "If the elements of the existent are not without parts, then the elements of the existent are without parts". It is implausible that a natural law holds between antecedent and consequent. Indeed, I am surprised that the 'natural law' interpretation of the conditional gained any currency, considering that this very example is one of the few that remain to us; and it is ironic that Mates painstakingly draws our attention to it. Thirdly, a Diodorean conditional may be true even if it lacks the constant conjunction between antecedent and consequent that is essential to natural laws. For instance, a conditional in which the consequent simply goes out of existence, while the antecedent continues to exist, can nonetheless be true on Diodorus' terms.

Finally, certain 'paradoxes' regarding Diodorean implication observed by the Kneales $(1962,132)$ sit uneasily with expressions of natural laws. In place of their list, let me suggest: 
(a) Any two propositions that are both true whenever one is, form a true Diodorean conditional in either order.

(b) Given two propositions that remain true once they become true, the Diodorean conditional with the proposition that becomes true later as antecedent, and the other as consequent, is true.

These exploit our reading of $p \rightarrow_{\triangleright} q$ as 'whenever $p, q$ '. Now it is easy to find true Diodorean conditionals that look nothing like natural laws: e.g.

"If it is May 31, 2003 then it is my wedding day", or "If Martha Kneale has lived, then Diodorus has lived".

To conclude: presumably Diodorus sought a conditional on which arguments and scientific inferences could be based. The Philonian conditional did not meet this need, as it did not capture a notion of necessity in the relationship between antecedent and consequent. However, I have argued that this necessity should not be understood as one of lawful connection, which is surely a strictly stronger relationship.

\section{The Chrysippean conditional}

The Diodorean conditional does not require any internal connection between antecedent and consequent for its truth. Perhaps for this reason, some Stoics rejected it, proposing instead a conditional whose truth did hinge on there being such a connection. Recall Sextus' words: “Those who introduce 'cohesion' say that a conditional is sound whenever the contradictory of its consequent 
conflicts with its antecedent." This view is commonly attributed to Chrysippus, and hereafter I will speak of the Chrysippean conditional. The interpretive problem for us is to understand the force of the words 'cohesion' and 'conflict'. 'Cohesion' has something of the flavour of law-like connection; 'conflict', which we may also translate as 'incompatibility', perhaps suggests logical impossibility. Thus, we will find ourselves asking the same questions of the Chrysippean conditional as we did of the Diodorean.

\section{Is the Chrysippean conditional strict implication?}

I find this the most difficult question of this paper, since it is the least obvious that its correct answer is "No"! The definition of a true Chrysippean conditional almost reads like a logic textbook definition of C. I. Lewis' strict implication. This interpretation is favoured by such luminaries as Mates, the Kneales, and Sedley (1984). Let us examine what light they shed on the question before us.

Mates (1953) appears to adopt this interpretation with alacrity: he writes that Chrysippean implication "is the ancient equivalent of what is now called 'strict implication'" (42). Again, "Chrysippean implication is that which holds between the members of a conditional which is logically true, that is, true of all possible worlds" (49). His evidence for this interpretation appears to be twofold. Firstly, he observes that Sextus presents the four conditionals in increasing order of strength (110 ff.). The Chrysippean conditional is third on the list. Thus, Mates argues, the 'incompatibility' of the 
antecedent and the denial of the consequent is logical-i.e. the conjunction of these propositions is logically false. The example of a true Chrysippean conditional that Sextus gives seems to support this: "If it is day, then it is day". However, I think that Mates moves too quickly here. Granted, the Chrysippean conditional is clearly a stronger conditional than the Diodorean, or else Sextus' ordering would be perverse. However, this does not force its strength to be that of strict implication; it may instead have a strength intermediate between the two. If so, Sextus' example would also come out true.

Mates' second piece of evidence (48-49) comes from a passage by Diogenes Laertius (Vitae VII, 77), which tells us that a valid argument is one such that "the negation of its conclusion is incompatible with the conjunction of its premises" (60). This definition is closely related to the truth conditions for the Chrysippean conditional. A combination of what we now call the deduction theorem and the conditionalization principle appears to be invoked here. We learn from modern logic than an argument is valid if and only if the conjunction of its premises strictly implies the conclusion (and nothing weaker than strict implication will do). I take this to be Mates' main rationale for identifying Chrysippean implication with strict implication.

However, this assumes that the Stoic conception of validity coincides with ours. This is surely implausible. For Sextus tells us that the Stoics judged arguments with a redundant premise to be 
invalid:

Argument is invalid through redundancy when something extraneous is superfluously added alongside the premises, as in 'If it is day, it is light. But it is day. But also virtue benefits. Therefore it is light'. For the premise that virtue benefits is superfluously added alongside the other premises, if on its removal it is possible through the remainder, 'If it is day, it is light' and 'But it is day', for the conclusion 'Therefore it is light' to be deduced. (Long and Sedley 1987a, 215).

By contrast, on the modern conception this argument is valid, and more generally, valid arguments cannot be rendered invalid by adding a further premise. In sum, Mates sees that the Stoics identify what they called 'valid arguments' with arguments that meet a certain criterion of theirs, and that we also identify what we call 'valid arguments' with arguments that meet a certain criterion of ours. Assuming that we and the Stoics mean the same thing by 'valid argument', our criteria must coincide. However, it is this very assumption that I am questioning.

The Kneales also seem to interpret the Chrysippean conditional as strict implication. They write: "it seems likely that [the third view of conditionals was] formulated by philosophers who had in mind the use of conditionals in place of entailment statements" (134). However, I find their subsequent commentary confusing, and I suspect confused. They point out, quite reasonably, that one cannot in general assume that the antecedent of a true conditional entails its consequent. But they then add that the philosophers who talked of connection ( $\sigma v \vee \alpha$ ' $\rho \tau \varepsilon \sigma \imath \sigma$ ) were committed to the "erroneous view that the antecedent of a true conditional does 
entail its consequent". The philosophers referred to are the followers of Chrysippus. But the very point of the Chrysippean truth conditions (on this interpretation) is to ensure that the antecedent of a true conditional entails its consequent. Far from subscribing to an erroneous view, the followers of Chrysippus appear (on this interpretation) to be those most aware of the need for particularly strong truth conditions on conditionals, realizing that without them, conditionals could not be statements of entailment. It's as if the Kneales were to reprimand C. I. Lewis for being committed to the "erroneous" view that whenever $p \rightarrow q$ is true, $p$ entails $q$ !

Sedley (1984) is another author who interprets the Chrysippean conditional in this way: "[Chrysippus] apparently restricted "if" to cases of logically necessary implication." It is puzzling that he cites here Frede's (1974), as if this view were also propounded there. But it is not. However, this is a good opportunity for me to put forward the view that I believe is Frede's; in any case, it is mine.

There are examples of conditionals that it seems Chrysippus would have found true, yet that are not examples of logical implication-e.g. "If something is human, it will die". We might call the incompatibility that exists between the antecedent and negated consequent of such conditionals 'natural incompatibility'. Their incompatibility is due to something in the essential natures of the things in question-mortality is of the very essence of the nature of human beings, for instance. There are two important points to understand about this notion. Firstly, it is stronger than 'physical 
incompatibility', there being a law of nature prohibiting the conjunction of these propositions. Rather, it is an incompatibility in the intrinsic nature of things, obtaining between antecedent and consequent in their own right. Secondly, while this incompatibility is something that we can become aware of in virtue of our reason, it is not of a purely conceptual nature. Rather, it is grounded in a real relation between antecedent and consequent, on a real connection between states of affairs. Thus, what I take to be Frede's interpretation, and in any case my interpretation, locates Chrysippean implication in strength intermediately between Diodorean and strict implication, the possibility of which I alluded to earlier.

I also found reason to place the relation of law-like connection intermediately between Diodorean and strict implication. The following question thus naturally suggests itself:

\section{Does the Chrysippean conditional express natural law?}

Gould (1967) gives a somewhat lengthy discussion of an argument given by Cicero (1991), which is apparently meant to be a reductio of Chrysippus' view of conditionals. Here it is in the original Latin (from Sharples 1991, 62-64):

si enim est verum quod ita conectitur, 'Si quis oriente Canicula natus est, in mari non morietur', illud quoque verum est, 'Si Fabius oriente Canicula natus est, Fabius in mari non morietur.' pugnant igitur haec inter se, Fabium oriente Canicula natum esse et Fabium in mari moriturum; et quoniam certum in Fabio ponitur natum esse eum Canicula oriente, haec quoque pugnant, et esse Fabium et in mari esse moriturum. ergo haec 
quoque coniunctio est ex repugnantibus, 'Et est Fabius et Fabius in mari morietur,' quod ut propositum est ne fieri quidem potest. ergo illud 'Morietur in mari Fabius' ex eo genere est quod fieri non potest. omne igitur, quod falsum dicitur in futuro, id fieri non potest.

Here is the translation by Sharples (1991, 63-65):

... if the conditional "If anyone has been born with the Dogstar rising, he will not die at sea" is true, then so too is "If Fabius has been born with the Dogstar rising, Fabius will not die at sea." So these things are incompatible, namely that Fabius has been born with the Dogstar rising and that Fabius will die at sea; and since it is supposed as certain in the case of Fabius that he has been born with the Dogstar rising, these things also are incompatible, namely that Fabius exists and that he will die at sea. So the following conjunction, too, is a combination of things that are incompatible: "Fabius exists, and Fabius will die at sea". Put forward this way, this cannot actually happen. So "Fabius will die at sea" belongs to the class of what cannot happen. Therefore everything which is said to be false in the future cannot happen.

Cicero appears to assume that a key conditional in the argument is Chrysippean; its appearance in the argument will thus give us an important clue to what Cicero took its truth conditions to be. On the basis of this argument, Gould judges Chrysippean conditionals "to be expressive of natural laws" (160). An analysis of the case that he makes will form the bulk of this section. In fact, only a small part of his discussion of Cicero's argument is relevant to his conclusion, but it will nonetheless be handy for us to have before us Gould's reconstruction of the argument (158):

\section{CICERO'S ARGUMENT (as presented by Gould)}

(1) If the proposition, 'if anyone is born at the rising of the dogstar, he will not die at sea,' is true, then

(2) the proposition, 'if Fabius is born at the rising of the dogstar, Fabius will not die at sea,' is true. And, therefore,

(3) 'Fabius was born at the rising of the dogstar' and 'Fabius will die at sea' are incompatible. And this assertion, combined with 
'Fabius was born at the rising of the dogstar,' enables us to infer that

(4) 'Fabius lives' and 'Fabius will die at sea' are incompatible propositions. Therefore

(5) 'Fabius lives and Fabius will die at sea' is an impossible conjunction. But, since 'Fabius lives' is true,

(6) 'Fabius will die at sea' belongs to a class of impossible propositions; and, from this, it may be concluded that

(7) that which is asserted falsely about the future is impossible.

Gould criticizes this argument as follows:

It ought to be observed, however, that step (6) can be inferred from step (5) only if Diodorus' doctrine concerning false propositions about the future is presupposed. The truth, that is, of 'Fabius lives' together with the negation of the conjunction, 'Fabius lives and Fabius will die at sea' entails the falsity of 'Fabius will die at sea,' but not the impossibility of Fabius' dying at sea one day, unless the doctrine disavowed by Chrysippus, what will never be true is impossible, be presupposed. (158)

The inference at issue has the form:

' $U$ and $V$ ' is an impossible conjunction.

' $U$ ' is true.

$\therefore$ ' $\mathrm{V}$ ' is impossible.

This is indeed a fallacious inference. But there is another way to salvage it besides the question-begging one that Gould recognizes: replace the second premise by:

' $U$ ' is necessarily true.

And as I will shortly show, Cicero could have repaired his argument with such a move. Moreover, Gould fails to point out other problems with the argument above, and these will give us a clue as to how to strengthen it.

The first concerns the derivation, from (1) and (2), of (3). Now (1) and (2) are not really two separate premises, but a single premise, namely a conditional of the form: 
(1)' If the proposition $X$ is true, then the proposition $Y$ is true, where $X$ and $Y$ are each conditionals:

$X=$ 'if anyone is born at the rising of the dogstar, he will not die at sea', and

$Y=$ 'if Fabius is born at the rising of the dogstar, Fabius will not die at sea'.

The words 'And, therefore' at the end of (2) suggest that (3) is meant to follow from this. In fact, a step has been left out here. (3) spells out the Chrysippean truth conditions of the conditional $Y$, so before deriving (3) we should have derived

(2)' $Y$ is true.

But now the illicit inference has been exposed. (2)' does not follow from (1)' alone, but rather from (1)' combined with

$(0)^{\prime} X$ is true.

Gould assumes that Chrysippus would accept (0)'-in fact, as we shall see, this assumption is pivotal to his whole case for the Chrysippean conditional expressing natural law, for $X$ is intended to be a natural law. This assumption is mistaken, as I will argue later, but let us accept it for the sake of the argument for now.

The second problem with Cicero's argument is the derivation of (4) from (3). The sly replacement of 'Fabius was born at the rising of the dogstar' by 'Fabius lives' is not only illicit-it is also counterproductive! After all, the goal is to derive the impossibility of 'Fabius will die at sea', and the best prospect for doing so is to appeal to the astrological 'law' that connects Fabius' being born at 
the rising of the dogstar to his not dying at sea. We have no reason to believe that his merely living lawfully determines his not dying at sea. The argument will actually have more force if we simply omit (4). In its place, let us derive from (3) (using obvious abbreviations):

(4)' 'FWBATROTD and FWDAS' is an impossible conjunction.

This follows from (3) and the definition of "incompatible".

Another problem with the original argument, which I have foreshadowed, occurs at (5), and the inference criticized by Gould. (5) really consists of two premises. The second premise, “'Fabius lives' is true"

is surely too weak to ground the inference to a claim of impossibility $-I$ agreed above that the inference is fallacious. But I also pointed out how the required inference can be salvaged, without presupposing the Diodorean doctrine concerning false propositions about the future (which would be question-begging). Instead of (5), and making no sly replacements, I propose:

(5)' 'FWBATROTD' is a truth about the past.

By a principle subscribed to by Chrysippus himself, truths about the past are necessary. 'Fabius lives', by contrast, is merely a truth about the present, and there is no corresponding necessity principle for truths about the present. If it is a necessary truth, (5)', unlike (5), is strong enough to render valid the resulting inference.

My final objection to the original argument is the derivation of (7) from (6). The false assertion about the future that Fabius will die at sea may be impossible without this implying that all false assertions 
about the future are impossible. Perhaps it is assumed that any false assertion about the future can be proven to be impossible by a similar sequence of steps; but if so, this should be a premise of the argument. This in turn assumes than any assertion about the future comes under the domain of a (astrological) 'law', such as $X$.

We are now in a position to give a better version of Cicero's argument:

\section{CICERO'S ARGUMENT REFORMULATED}

(0)' $X$ is true.

(1)' If $X$ is true then $Y$ is true.

Hence,

$(2)^{\prime} Y$ is true.

Then replacing $Y$ by the conditional for which it stands, and applying Chrysippus' truth conditions to this conditional:

(3)' 'Fabius was born at the rising of the dogstar' and 'Fabius will die at sea' are incompatible.

Hence,

(4)' 'FWBATROTD and FWDAS' is an impossible conjunction.

But

(5)' 'FWBATROTD' is a truth about the past.

Therefore,

(6)' 'FWBATROTD' is necessarily true.

Thus, from (4)' and (6)',

(7)' 'FWDAS' is impossible.

Now, to generalize this argument:

(8)' Any assertion about the future comes under the domain of a (astrological) 'law' such as $X$.

Therefore,

(9)' Any false assertion about the future can be proven to be impossible by a sequence of steps similar to (0)' - (7)' (replacing

$(0)^{\prime}$ ' by the relevant 'law', the existence of which is guaranteed by

(8)').

Hence,

(10)' That which is asserted falsely about the future is impossible.

If, as Gould assumes, Chrysippus really accepted premise (0)', 
then I see no way out for him this time-he would have to face the uncomfortable conclusion that Fabius' not dying at sea is a necessary truth. Furthermore, if he believed that for any future event, there is an appropriate counterpart to $(0)^{\prime}$, then he would have to accept the necessity of all future events.

But would Chrysippus really accept premise (0)'? Gould writes (of proposition $X$ ): "had the proposition not satisfied the truth condition approved by Chrysippus, he could have said so and gotten his embarrassment in that way" (157). Unfortunately, Chrysippus had been dead for over a hundred and fifty years by the time Cicero wrote De Fato, so it would not have been easy for him to "have said so"! I am not merely being facetious here, for we must remember that the passage in question was not written by Chrysippus, but by a commentator on him-and an unsympathetic commentator at that. Our first task, then, should be to scrutinize the reliability of Cicero.

We have already cast some doubt on Cicero's logical acumen in our exposure of the many flaws in his argument above. This is clearly not the work of a skilled logician. More evidence of his failings as a commentator are close at hand. Shortly after the passage we have been examining we find the following:

medicus in primis quod erit ei perspectum in arte non ita proponet, 'Si cui venae sic moventur, is habet febrim', sed potius illo modo, 'Non et <cui> venae sic moventur et is febrim non habet.' itemque geometres non ita dicet, 'In sphaera maximi orbes medii inter se dividuntur,' sed potius illo modo, 'Non et sunt in sphaera maximi orbes et ii non medii inter se dividuntur. (66) 
Here is the Sharples translation:

The doctor, first of all, will not put forward what has been observed by him in his skill as follows, "if someone's pulse is like this, that person has a fever", but rather, in the manner described, "it is not the case both that someone's pulse is like this and that that person does not have a fever." Similarly the geometrician will not say "Greatest circles on a sphere bisect one another", but rather, in the manner described, "it is not the case both that there are greatest circles on a sphere and that they do not bisect one another." (67)

Cicero's sarcasm exceeds his insight here. Firstly, "Greatest circles on a sphere bisect one another" is not a conditional, but a universal generalization. To serve Cicero's rhetorical purposes, it should be reformulated: "If there are greatest circles on a sphere, then they bisect on another"-then it at least has the right form to be paraphrased as a negated conjunction. More importantly, in his rhetorical fervour, he has missed an important distinction. Chrysippus was apparently at pains to distinguish conditionals based merely on empirical observation from those perceived by the intellect as expressing a cohesion or synártesis between states of affairs. The conditional involving the physician is of the former kind, and Cicero probably gauges Chrysippus' reaction to it correctly. However, the conditional involving the geometrician is of the latter kind, expressing as it does a necessary connection in the strongest possible sense. I am sure that Chrysippus would have had no qualms about its truth qua conditional. Cicero is clearly being unfair to Chrysippus here.

Now we can see that the linchpin of Gould's argument is suspect. 
He writes (of proposition $X$ ): "[Cicero] appears to me to be supposing that this kind of conditional proposition is one ... which satisfies a criterion of truth approved by Chrysippus" (158). I agree: I grant that Cicero does suppose this. However, a page later we find that Gould has slid to a stronger claim: "Cicero must have used a conditional proposition true in the Chrysippean sense." This is going too far. Granted, Cicero must have thought that he was using a conditional proposition that was true in the Chrysippean sense, but this by no means guarantees that he was using such a conditional. We have already seen ample evidence of his fallibility.

Gould infers from (3) in the original argument that, in Chrysippus' view, a conditional proposition is true when the negation of its consequent is incompatible with its antecedent. I agree. But he continues: “... it does not appear that logical incompatibility is intended here ... the incompatibility is rather of an empirical nature" (159). He concludes that Chrysippean conditionals are expressive of natural laws.

Gould owes us an account of why Chrysippus urges the use of the negated conjunction over the conditional. If, as Gould believes, the conditional expresses nothing more than the empirical incompatibility between antecedent and negated consequent, then it appears to be a mere stylistic variant of the corresponding negated conjunction. Gould might reply, as Cicero did, that Chrysippus just "became agitated" ("aestuans falli"), desperately trying to avoid his position collapsing into that of Diodorus. Running 
this argument in reverse, however, and I find this more plausible, Gould's interpretation appears to conflate Diodorean implication with Chrysippean implication, whereas we know that the two are distinct-the passage from Sextus already makes this clear. Elsewhere, Cicero writes that on the truth conditions of a conditional, "Diodorus holds one view, Philo another, Chrysippus another" (1991, 47). How can Gould account for this? Even he admits, regarding this point: "our interpretation confronts us with a difficulty. For it begins to appear that Chrysippean implication does not differ from that of Diodorus, because we take Chrysippean conditionals to be expressive of natural laws" (160). The unstated assumption here is that Diodorean conditionals should also be regarded as expressive of natural laws. I have argued against this in an earlier section. But let us press on.

In attempting to salvage the distinction that Cicero and Sextus allude to, Gould suggests that Chrysippean implication "may have been regarded in some extended sense of the term, as analytic" (161). We are left wondering just how "extended" the sense is. It is debatable whether the Stoics had any notion corresponding to what we call "analytic" (even in an "extended sense"). Even if they did, it would take a very extended sense of the term indeed to find "if Fabius was born at the rising of the dogstar, then he will die at sea" to be 'analytic'!

To conclude, Gould admits that an unhappy feature of the view to which he appears to subscribe is that "it means we must foist upon 
the minds of logicians in antiquity a confusion of empirical impossibility and logical impossibility" (161). I suggest that we foist the confusion upon the mind of Cicero, and leave it there. It is ironic that Gould ends with a quote from Lewis and Langford to the effect that empirical impossibility and logical impossibility are frequently confused, "with consequences which are fatal to the understanding of logical principles" (161).

I conclude, contra Gould, that Chrysippean implication is something stronger than an expression of natural law.

\section{Conclusion}

We are now in a position to order all of the relations that I have considered on a single scale. I offer the following 'ladder', in increasing order of strength:

Philonian implication

Diodorean implication

Constant conjunction

Natural law

Chrysippean implication

Strict implication

(and finally perhaps, the 'fourth' conditional).

This is a strict ordering in the sense that no two of these relations have the same strength. This leaves us with problems of fine-tuning, but as for the exact placements of these relations on the scale of logical strength, I will not speculate. That said, my placement is 
informative enough to answer negatively all four of the questions that have charted our course through this paper. ${ }^{2}$

Philosophy Program Research School of Social Sciences Australian National University Canberra, ACT 0200 Australia

\section{REFERENCES}

Armstrong, D. M. (1983): What is a Law of Nature?, Cambridge: Cambridge University Press.

Chisholm, R. (1941): “Sextus Empiricus and Modern Empiricism”, Philosophy of Science 8, No. 3, 371-384.

Cicero (1991): De Fato (On Fate). Reprinted in the original Latin and translated in Sharples 1991.

Dretske, F. (1977): “Laws of Nature”, Philosophy of Science 44, 248-68.

Gould, J. (1967): "Chrysippus: On the Criteria for the Truth of a Conditional Proposition", Phronesis 12, 152-61.

Frede, Michael (1974): Die Stoische Logik, Göttingen.

Hurst, M. (1935): “Implication in the Fourth Century B.C.", Mind 44, 1935, 484-495.

Kneale, W. and M. (1962): The Development of Logic, Oxford: Oxford University Press.

Lewis, D. (1973): Counterfactuals, Cambridge MA: Harvard University Press.

Long, A. A. and D. N. Sedley (1987a): The Hellenistic Philosophers, Volume 1: Translations of the Principal Sources with Philosophical Commentary,

2 I am indebted to Michael Frede, an inspirational teacher, for his help and encouragement on an early draft of this paper; and to Ralph Miles for editorial assistance in the final stages. 
Cambridge: Cambridge University Press.

Long, A. A. and D. N. Sedley (1987b): The Hellenistic Philosophers, Volume 2: Greek and Latin Texts, with Notes and Bibliography, Cambridge: Cambridge University Press.

Mates, B. (1949): “Diodorean Implication”, The Philosophical Review 58, 234-242.

Mates, B. (1953): Stoic Logic, Berkeley/Los Angeles: University of California Press.

McCall, S. (1994): A Model of the Universe, Oxford: Oxford University Press.

Mueller, I. (1969): "Stoic and Peripatetic Logic", Archiv für Geschichte der Philosophie 51, 173-87.

Pargetter R. (1984): “Laws and Modal Realism”, Philosophical Studies 46, 335-47.

Prior, A. (1955): “Diodorean Modalities”, Philosophical Quarterly 5, 205-213.

Prior, A. (1957): Time and Modality, Oxford: Oxford University Press.

Sedley, D. (1984): “The Negated Conjunction in Stoicism”, Elenchos 5, 311-16.

Sharples, R. W. (1991): Cicero: On Fate (De Fato) \& Boethius: The Consolation of Philosophy (Philosophiae Consolationis) IV.5-7, V, Warminster: Aris \& Phillips Ltd.

Tooley, M. (1987): Causation, a Realist Approach, Oxford: Clarendon Press.

Vallentyne, P. (1988): “Explicating Lawhood”, Philosophy of Science 55, 598-613.

van Fraassen, B. (1989): Laws and Symmetry, Oxford: Clarendon Press. 